\title{
16th International Workshop on Advanced Infrared Technology and Applications (AITA 2021) ${ }^{\dagger}$
}

\author{
Paolo Bison ${ }^{1}(\mathbb{D})$, Gianluca Cadelano ${ }^{2} \mathbb{D}$, Mario D'Acunto ${ }^{3}(\mathbb{D})$, Giovanni Ferrarini ${ }^{1} *(\mathbb{D})$, Xavier Maldague ${ }^{4}(\mathbb{D}$, \\ Davide Moroni ${ }^{5}$ (D), Valentina Raimondi ${ }^{6} \mathbb{D}$, Antoni Rogalski ${ }^{7}$, Takahide Sakagami ${ }^{8}$, Marija Strojnik ${ }^{9}$ \\ and Monica Volinia 10
}

check for updates

Citation: Bison, P.; Cadelano, G.; D'Acunto, M.; Ferrarini, G.;

Maldague, X.; Moroni, D.; Raimondi,

V.; Rogalski, A.; Sakagami, T.;

Strojnik, M.; et al. 16th International

Workshop on Advanced Infrared

Technology and Applications (AITA

2021) Eng. Proc. 2021, 8, 34.

https://doi.org/10.3390/

engproc2021008034

Published: 6 January 2022

Publisher's Note: MDPI stays neutral with regard to jurisdictional claims in published maps and institutional affiliations.

Copyright: () 2022 by the authors Licensee MDPI, Basel, Switzerland. This article is an open access article distributed under the terms and conditions of the Creative Commons Attribution (CC BY) license (https:// creativecommons.org/licenses/by/ $4.0 /)$.
1 Consiglio Nazionale delle Ricerche, Istituto per le Tecnologie della Costruzione, 35127 Padova, Italy; paolo.bison@itc.cnr.it

2 Consiglio Nazionale delle Ricerche, Istituto per le Scienze dell'Atmosfera e del Clima, 35127 Padova, Italy; g.cadelano@isac.cnr.it

3 Consiglio Nazionale delle Ricerche, Istituto di Biofisica, 56124 Pisa, Italy; mario.dacunto@ibf.cnr.it

4 Computer Vision and Systems Laboratory, Department of Electrical and Computer Engineering, Laval University, Quebec City, QC G1V 0A6, Canada; xavier.maldague@gel.ulaval.ca

5 CNR-ISTI, Consiglio Nazionale delle Ricerche, Istituto di Scienza e Tecnologie dell'Informazione "A. Faedo", 56124 Pisa, Italy; davide.moroni@isti.cnr.it

6 Consiglio Nazionale delle Ricerche, Istituto di Fisica Applicata “N. Carrara”, 50019 Sesto Fiorentino, Italy; v.raimondi@ifac.cnr.it

7 Institute of Applied Physics, Military University of Technology, 01-476 Warsaw, Poland; antoni.rogalski@wat.edu.pl

8 Department of Mechanical Engineering, Kobe University, Kobe 657-850, Japan; sakagami@mech.kobe-u.ac.jp

9 Optical Research Center, A. P. 1-948, Leon C.P. 37000, Guanajuato, Mexico; mstrojnik@gmail.com

10 Department of Architecture and Design, Politecnico di Torino, 10129 Torino, Italy; monica.volinia@polito.it

* Correspondence: giovanni.ferrarini@itc.cnr.it

+ Presented at the 16th International Workshop on Advanced Infrared Technology \& Applications, 26-28 October 2021; Available online: https:/ / aita2021.sciforum.net/.

Abstract: The 16th International Workshop on Advanced Infrared Technology and Applications (AITA 2021) was held online on 26-28 October 2021.

Keywords: non-destructive testing and evaluation; remote sensing; environmental monitoring; materials; bio-medical applications; image processing

\section{Introduction}

Since 1992, AITA is an international conference aimed to assess the state of the art of technology in the infrared bands and to present its most interesting applications. The last AITA was held in Florence in 2019, where the idea of this conference series was launched 25 years ago, thanks to the efforts and commitment by the Fondazione "Giorgio Ronchi" led by Prof. Laura Ronchi Abbozzo.

The 2021 edition was planned to be organized in Venice, but due to the pandemic situation, it was impossible to hold an in-person meeting. To keep the flame alive in spite of the persisting situation, the 16th International Workshop on Advanced Infrared Technology and Applications (AITA 2021) has been organized as an online event by:

- $\quad$ Istituto per le Tecnologie della Costruzione (CNR-ITC);

- Istituto di Fisica Applicata "Nello Carrara" (CNR-IFAC);

- $\quad$ Istituto di Scienza e Tecnologie dell'Informazione “Alessandro Faedo" (CNR-ISTI);

- $\quad$ Istituto di Biofisica (CNR-IBF);

- $\quad$ Istituto di Scienze dell'Atmosfera e del Clima (CNR-ISAC);

- Politecnico di Torino;

- Fondazione "Giorgio Ronchi". 
Moreover, two institutions have offered their patronage to the event: The Italian Association of Infrared Thermography, Diagnostics and Condition Monitoring (AITI-DMC) and the Italian Society for Nondestructive Testing and Monitoring Diagnostics (AIPnD).

\section{Conference Days}

The event was held online from 26 to 28 October 2021. The technical program was organized in six sessions covering the following topics: the Under 35 Best paper award, Non-destructive testing, Remote sensing and environmental monitoring, Materials, BioMedicals and Image processing.

Each day, the Conference was divided in a pre-recorded session and a live session. The daily pre-recorded session presentations were streamed thrice to accommodate the different time zones. The live panel discussion was placed at the end of the streaming session and included keynotes, question and answer (Q\&A) and sponsor presentations. In spite of the limited available time, the authors had the possibility to provide interesting additional information to the works they had submitted to the conference.

A plenary lecture was delivered by Prof. Jean-Christophe Batsale from ENSAM in Bordeaux, France. His contribution, entitled "Multispectral and multiscale infrared imaging for the study of heat and mass transfer in heterogeneous media", described interesting applications that, starting from the physical modeling of the Thermal Non-Destructive Evaluation of delaminations in composite materials, extends to the evaluation of anisotropic thermal diffusion. Novel and worthwile results have been shown in the assessment of thermophysical properties of heterogeneous materials and in mapping the flow distribution from NIR to THz.

Almost 40 papers were submitted to the conference and are published in a Special Issue of MDPI's Engineering Proceedings [1].

\section{Fifth under 35 Best Paper Award}

For the fifth time in the AITA Conference, the AITA Committee assigned a best paper award to presenting authors under 35 years old. The award is named after Ermanno Grinzato, AITA co-chairman for a long time and known scientist in the thermography community. The award supports young scientists that are involved in scientific research on the conference topics.

The nine candidates submitted works of high interest for the AITA community and, due to the quality of their contributions, the award committee decided to assign the prize to three authors, equally placed:

- Jue Hu (3D non-destructive inspection using novel infrared-terahertz fusion approaches) [2];

- $\quad$ Ryohei Fujita (Micro-scale Fatigue Damage Assessment of CFRP Laminates Using Lock-in Thermography) [3];

- $\quad$ Giuseppe Dell'Avvocato (Evaluation of effectiveness of heat treatments in boron steel by laser thermography) [4].

\section{Committees}

General chair

L. Ronchi Abbozzo Co-Chair

P. Bison

M. D'Acunto

X. Maldague

D. Moroni

V. Raimondi

A. Rogalski

T. Sakagami

M. Strojnik
Fondazione Giorgio Ronchi, Firenze, Italy

CNR-ITC, Padova, Italy

CNR-IBF, Pisa, Italy

Laval University, Quebec City, QB, Canada

CNR-ISTI, Pisa, Italy

CNR-IFAC, Firenze, Italy

Military University of Technology, Warsaw, Poland

Kobe University, Kobe, Japan

CIO, León, Guanajuato, Mexico 


\section{Scientific Committee}

D. Balageas

E. Dereniak

C.T. Elliott

C. Maierhofer

C. Meola

H.N. Rutt

G. Steenackers

V.P. Vavilov

M. Volinia

Organizing Committee

P. Bison

G. Cadelano

M. D'Acunto

G. Ferrarini

D. Moroni

V. Raimondi

M. Volinia

Technical Support

S. Rossi

M. Tampucci
ONERA, Chatillon, France

University of Arizona, Tucson, AZ, USA

Heriot-Watt University, Edinburgh, Scotland

BAM, Germany

University of Napoli, Napoli, Italy

Southampton University, Southampton, United Kingdom

University of Antwerp, Antwerp, Belgium

Tomsk University, Tomsk, Russia

Politecnico of Torino, Torino, Italy

CNR-ITC, Padova, Italy

CNR-ISAC, Padova, Italy

CNR-IBF, Pisa, Italy

CNR-ITC, Padova, Italy

CNR-ISTI, Pisa, Italy

CNR-IFAC, Firenze, Italy

Politecnico di Torino, Torino, Italy

CNR-ITC, Padova, Italy

CNR-ISTI, Firenze, Italy

Funding: This research received no external funding.

Acknowledgments: We would like to thank the companies Teledyne FLIR, Telops and Horiba for supporting this event.

Conflicts of Interest: The authors declare no conflict of interest.

\section{References}

1. AITA Conference Proceedings. Available online: https://www.mdpi.com/2673-4591/8/1 (accessed on 30 December 2021).

2. Hu, J.; Zhang, H.; Sfarra, S.; Santulli, C.; Maldague, X. Three-Dimensional Non-Destructive Inspection Using Novel InfraredTerahertz Fusion Approaches. Eng. Proc. 2021, 8, 24. [CrossRef]

3. Fujita, R.; Katsukura, K.; Nagano, H. Micro-Scale Fatigue Damage Assessment of CFRP Laminates Using Lock-in Thermography. Eng. Proc. 2021, 8, 2. [CrossRef]

4. Dell'Avvocato, G.; Palumbo, D.; Palmieri, M.E.; Galietti, U. Evaluation of Effectiveness of Heat Treatments in Boron Steel by Laser Thermography. Eng. Proc. 2021, 8, 8. [CrossRef] 